\title{
Rir para enganar o olhar do censor A revista portuguesa e o grotesco
}

\author{
Graça dos Santos
}

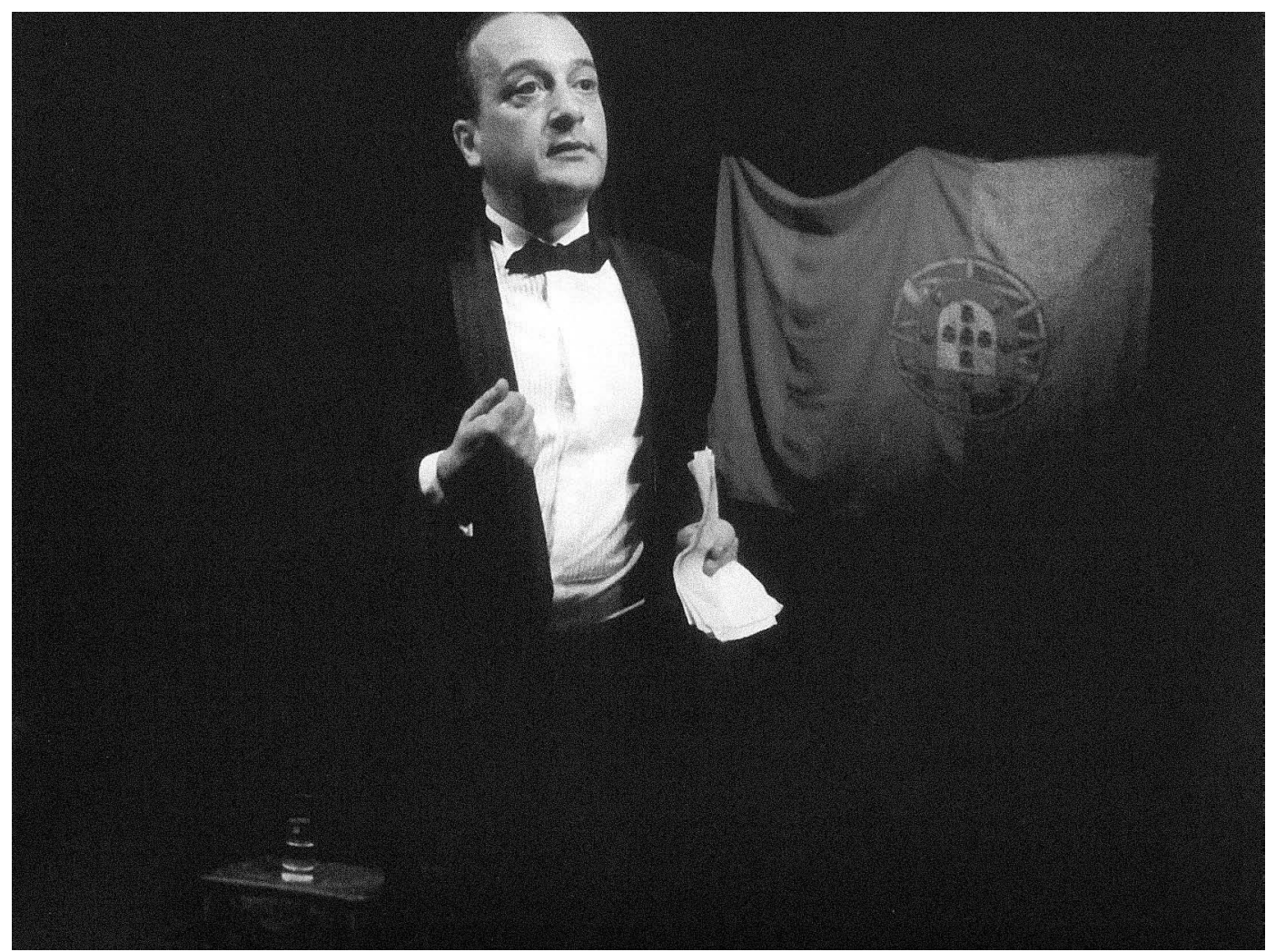

"Um suspiro de saudade"

Interrogado sobre o lirismo da alma portuguesa,

Antonio Tabucchi refere-se à saudade e, logo a seguir, a um verso de Maria Parda de Gil Vicente, "e a cada traque que eu dou, é um suspiro de saudade", que ele identifica como um fil rouge que, desde as origens, percorre o espírito português, também na sua expressão literária, com as cantigas de escárnio e de mal-dizer consideradas intelectual e institucionalmente como o parente pobre das cantigas de amigo. "Há, nos portugueses, um veio pícaro forte, um escárnio sempre presente, uma maldadezinha, um tom mais baixo, rabelaisiano. Que todavia o poder cultural sempre põe de lado (o que também acontece noutras culturas), porque é mais nobre eleger a tal outra 'saudade' a lírica, como veio fundador" (Tabucchi 2000). E constata que, de Gil Vicente, são mais referidos os autos associados com o "sublime" e evitam-se as comédias e as farsas povoadas por personagens mal cheirosas e rotas, pelintras como a Maria Parda. Este gracejo e este-mal dizer estão associados a uma forma de autodenegrimento que se compraz na crítica acerba do outro.

Esta especificidade cultural é evocada por alguns autores, mas nenhum the consagrou um estudo global. Por entre os que lamentam esta carência, João Medina colabora no desenho de um traço que nenhum poder jamais conseguiu apagar totalmente e que ele descreve como a "tendência lusa para o escárnio maledicente" (Medina 2006: 74). E evoca exemplos desde a literatura medieval até à imprensa satírica do século XIX, citando Almada Negreiros e o Manifesto anti-Dantas como "exemplo típico do sarcasmo paródico nacional" e enaltecendo António Lobo Antunes com As naus (1988) pela "demolição sem complexos dos fundamentos mesmos da nossa vida e história colectivas". De passagem, o historiador evoca algumas figuras mediatizadas mais recentes como Mário Viegas (19481996), grande actor sarcástico que, como Coluche em
Mário Viegas,

Mário gin tónico, 1991 [cortesiaMuseu Nacional do Teatro].

Graça dos Santos é Maître de conférences na Université Paris Ouest Nanterre La Défense, onde é directora do Departamento de estudos lusófonos. Investigadora da EA 369 Études romanes, membro do CRILUS (Centre de recherches interdisciplinaires sur le monde lusophone) e do Centre d'Histoire Culturelle des Sociétés Contemporaines (Université Versailles St Quentin en Yvelines), codirige desde 2001 com Jean Claude Yon o seminário de investigação sobre história do espectácul ao vivo nos séculos XIX e XX, na Société d'Histoire du Théâtre, BNF Richelieu, Paris. Publicou

$O$ espectáculo desvirtuado: $O$ teatro português sob o reinado de Salazar (1933-1968). 
França ${ }^{1}$, se apresentou às eleições presidenciais; formas de humor cáustico popularizado pela televisão, através do exemplo mais recente do Gato Fedorento ou do programa Contra informação. Esta forma de humor, que não hesita em inspirar-se no mundo político, na actualidade ou na vida quotidiana, produz uma espécie de derrisão próxima do absurdo que ultrapassa as fronteiras nacionais.

\section{0 perigo do rir incontrolado}

Desde sempre, em todos os sítios, sempre se fez troça do poder e este sempre reagiu de maneira mais ou menos coerciva, porque o rir, embora definido por Rabelais como próprio do homem, é considerado uma ameaça ao pensamento dominante e às normas por ele definidas. Em relação à arte dramática, esta vigilância aperfeiçoou-se a fim de controlar os corpos soltos no palco, as palavras e as ideias inconvenientes, de modo a proteger o teatro de uma forma de riso demasiadamente invasora, capaz de contaminar o público de maneira incontrolada e sobretudo gratuita. São estas práticas que evocam o carnaval e levam a "gentalha" a espojar-se em licenciosas exibições de um humor, por isso mesmo, inaceitável. "O teatro, logo que renega as fontes populares e escolhe eliminar a linguagem do corpo da sua língua própria, tem por desígnio a ambição de remodelar o real que ele imita de produzir sentido, de se tornar útil para com a comunidade dos espectadores e para com a cidade" (Abirached 2003: 11).

\section{Nada de misturas}

As fundações do teatro português admitem a bipolaridade picaresca / lírica, já que Gil Vicente, como Rabelais, mistura numa só obra a elite e a corte, para quem escrevia, com o povo que mora nos seus textos; as suas farsas e os seus autos carregam linguagens e comportamentos em princípio antagónicos: o mal cheiroso relaxado para quem contam as aparências e face ao qua se tapa o nariz, que as conveniências ou a razão convidam a menosprezar. Este caminhar lado a lado será rapidamente apontado pela Santa Inquisição, que higienicamente limpará os palcos destas misturas. A separação será assinalável no domínio do texto, mas também na diferenciação do espaço: para uns, edifícios concebidos para receber um auditório educado, para outros, locais informais, ou até a rua, indicados para um público pouco asseado e indisciplinado. Historiadores do teatro vêem aqui a origem da bipolaridade entre o teatro declamado e o teatro ligeiro (cf. Abelho 1965). 0 teatro de revista teria nascido assim: o fado encontra na rua o teatro de cordel, produzindo formas espectaculares populares que se vão misturar sob a influência da revue française a partir de 1850. A especificidade da revista à portuguesa vem daí: mescla de coristas desvendando mais ou menos a anatomia, de música e de actores hábeis na chalaça que fazem desfilar no palco os protagonistas da sociedade portuguesa da altura. Os personagens são figuras tipificadas que servem para pôr a ridiculo a realidade política e social.

\section{Zé povinho, entre atracção e repulsa}

É aqui que se anicha o Zé povinho criado por Rafael Bordalo Pinheiro em 1875, que rapidamente se transforma no compère mais famoso da revista, fazendo a ligação entre os quadros que a compõem; aquele que João Medina vê como um "totem caseiro e um novo parvo vicentino, xabregas mas manhoso, como uma espécie de soldado Chveick lusitano" (Medina 2006: 206). É um Sancho Pança sem Dom Quixote e, por isso, totalmente à solta a rebolarse sem complexos na inconveniência; definitivamente parvo rural, pascácio desleixado, com a barba por fazer, com o inconfundivel chapéu braguês e evidenciando um sorriso aparvalhado, é tanto bode espiatório como escória, cortiça que flutua na água que corre sob as pontes do poder. Rapidamente se torna em símbolo popular e símbolo colectivo que ultrapassa a própria revista; mas é mais complexo do que parece: aparentemente resignado, há que não acreditar na sua placidez toda teatral; tal como o burro, do qual ostenta a albarda, pode dar um coice a qualquer momento. Suficientemente idiota para não ser credivel, insuficientemente inteligente para que se desconfie dele, a ele tudo se pode mandar dizer. Bobo que balança entre o grotesco e o burlesco, rebola-se desavergonhadamente na paródia passando de alhos para bugalhos até ao desnorteamento.

A sua reorganização do real participa duma figuração do kitsch, com o disfarce e a falcatrua por convenção, com a valorização da escória em detrimento do essencial. 0 personagem como modo de representar dos actores que desempenham o seu papel funciona por atracção e repulsa. Isto vai provocar um jogo de cabra cega com a censura, com mensagens codificadas destinadas ao público sôfrego por esse piscar de olhos. O Zé povinho é um parvo a quem se pode mandar dizer tudo porque o pressuposto é que não sabe o que diz. Mas todos, e sobretudo os espectadores, sabem que é um falso inocente que manda bocas ao poder. Este procedimento do compère mais importante da revista transita para esta forma de teatro português no seu conjunto. Forma controversa, inscrevese na ramificação menos reconhecida do teatro português, sendo-Ihe a "ligeireza" singularmente prejudicial e cortando-Ihe a aceitação do teatro dito declamado. 0 poder salazarista não parou de sublinhar essa dicotomia que fez tudo para eternizar: "0 teatro ligeiro (...) não precisa da política para nada (...) porque a política é sempre a realidade e o teatro ligeiro, cuja matéria-prima é a fantasia, deve ser o sonho, e a irrealidade que nos liberta do quotidiano, dos nossos azedumes e rancores, das nossas divergências" (Ferro 1956: 28). Este teatro não deve, pois, ser levado a sério e deve ser reduzido a um papel de diversão. 0 Estado Novo vai, assim, usá-lo como uma das válvulas de escape para garantir o poder. 


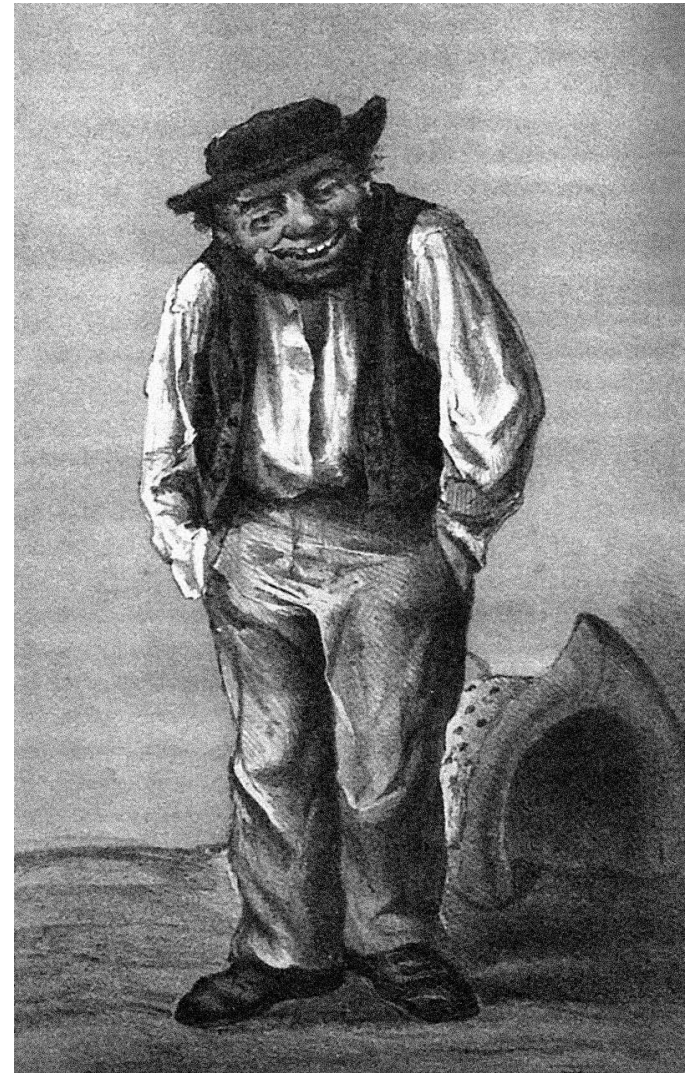

Esófago para a digestão do real

Ser-Ihe-ão permitidas liberdades noutros lugares impensáveis, ao mesmo tempo que é rebaixado: uma forma de teatro um pouco grosseiro, grotesco, no qual o público se envilece para melhor suportar as obrigações impostas por outro lado. Mas é um estilo que não deve ser levado a sério, objecto de aviltamento intelectual. Jorge de Sena não diz outra coisa: "É perfeitamente imoral que não aflija ninguém a obscenidade, inteiramente destituida de nobreza, 'escatológica'", que se consente aos revisteiros, e que não seja possivel tratar a sério, sem obscenidade, os mesmos temas" (Sena 1988: 298).

A triagem operada pela censura e pelo poder é muito hábil e age por ricochete: o teatro de revista, reduzido a um género "baixo" e intelectualmente menosprezado, neutraliza o alcance das mensagens nele contidas e as críticas feitas ao mesmo poder. Comercial por excelência, a revista serviu, em grande parte, de exutório para a sociedade do Portugal salazarista. Sofreu o lápis azul da censura, mas tentou sempre arranjar maneira de se manter no palco. Funcionou como uma espécie de esófago destinado a permitir a digestão dum real insuportável.

Esta reflexão necessitaria mais espaço para ser desenvolvida e completada. Parece-nos que a melhor maneira de a ilustrar e, parcialmente, de a explicitar é citando o monólogo de Hermínia Silva no papel de Antígona, na revista Sempre em pé, apresentada no teatro Avenida em 1946:

Senhor Robles, não se irrite, eu sou assim! / As tragédias são fadistas para mim! / sem querer recito a Antígona em calão, / sai-me um fado à velha Grécia que nem pão! / Eu bem quero declamar / e até representar / toda armada em grande lasca! / Mas não há nada a fazer, eu sou assim, / vejo as

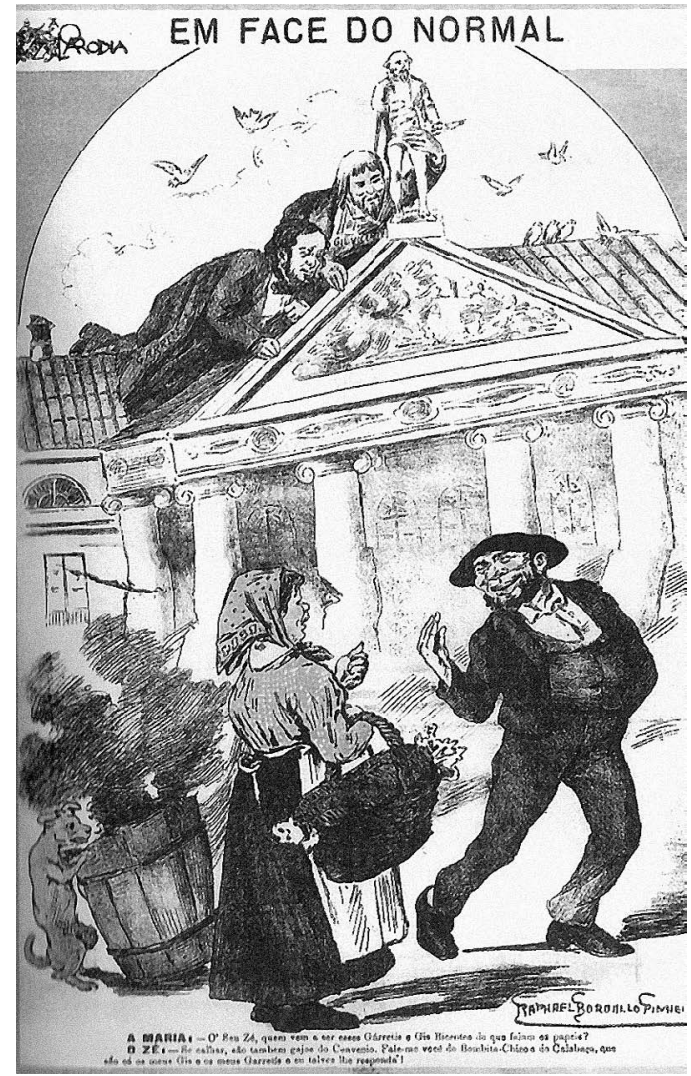

Zé Povinho,

"O Soberano!",

de Rafael Bordalo Pinheiro,

Album das glórias, Lisboa Frenesi, 2003, p. 132

"Em face do Normal", A paródia, n. 125 , 4 de Junho de 1902, pp.4-5. barbas do Creonte e fico à rasca! / represento hoje tragédia - e bem! / Podem crer que tenho jeito! / se a Mariana diz que tem, também / quero ter esse direito! / Cá p'ra gente o meu receio / não é ir p'ro Nacional, / é se eu largo uma bojarda em cheio / e o Sófocles fica mal! / As fadistas hoje em dia são assim: / mais Antígonas e Lencastres, dernier cri! / E as rainhas são a Amália, para mim / mais a T'resa de Noronha para ti ! / Era injusto, era arrelia / ficar eu na chungaria / e esta ideia eu pus em pé: / Já mandei fazer cenários ao Donnat/ e vou dar um recital c'o Villaret! / 0 teatro quer subir, crescer / e isto agora mete pilhas! / 'Té a mim no Nacional vão ver / na Electra de Cacilhas! / E para eu manter por cá / - olá! - / o meu nome sempre fixe / vou fazer a Miss Bá / - ó pá! - / da calçada de Carriche! (apud Rebello 1983: 100-101)

\section{Referências bibliográficas}

ABELHO, Azinhal (1965), "Teatro popular português", Espiral, n. 6-7, Verão, pp. 62-69.

ABIRACHED, Robert (2003), "Le rire sous surveillance", Théâtres en Bretagne, n. ${ }^{\circ}$ 17: Le rire interdit, 1. ${ }^{\circ}$ Semestre.

FERRO, António (1956), Teatro e cinema: 1936-1949, Lisboa, SNI. MEDINA, João (2006), Portuguesismo(s): Acerca da identidade nacional, Lisboa, Centro de História da Universidade de Lisboa, Faculdade de Letras da Universidade de Lisboa.

REBELLO, Luiz Francisco (1983), Portugal anos quarenta, Lisboa, Editorial Caminho.

SENA, Jorge de (1988), 0 teatro em Portugal, Lisboa, Edições 70. TABUCCHI, Antonio (2000), entrevistado por Maria João Seixas, Pública, 2 de Abril, pp. 22-29. 